\title{
The Influencing Factors of Cultural Knowledge in Translating Cultural Specific Concepts from Arabic into the English at Jazan University in Saudi Arabia
}

\author{
Amin Ali Almubark \\ Department of English Translation Jazan University, Saudi Arabia \\ E-mail: amino.last25@gmail.com
}

Received: 12-09-2016

Accepted: 26-11-2016

Advance Access Published: January 2017

Published: 01-03-2017

doi:10.7575/aiac.ijalel.v.6n.2p.106

URL: http://dx.doi.org/10.7575/aiac.ijalel.v.6n.2p.106

\begin{abstract}
This study was set out to explore and evaluate the importance of having mastered the cultural knowledge throughout the process of depicting the culture-specific concepts involving two languages namely Arabic and English. In doing so, the participants sampled in this study were a group of final year Bachelor's degree students majoring in Translation in ALAradha College at the Jazan University. The findings of the study method employed in this study statistically confirmed that the students of the Translation at AL AlAradh college- Saudi Arabia faced considerable difficulties throughout the process of translating cultural concepts owing to inadequate mastery of knowledge in relation to the culture involved. Among the measures which can be taken in addressing the issues in this context are training the learners by means of exposure to real cases involving culture-specific concepts which may help them deal with such difficulties in the translation process.
\end{abstract}

Keywords: Culture, Translation, Influencing factors

\section{Introduction}

Translation which involves different languages can be considered as an art and has now gradually become significant in today's world. It is usually the translators who are responsible for better and more accurate mechanisms of this art. This modern era in which drastic advancements in Information and Computer Technology are being made, the geographical separation is no longer an issue, hence the need for exchanging beliefs and ideas among different nations is therefore strongly felt. Possessing a decent knowledge about other people's experiences, level of knowledge, and cultural matters my help people in developing a better standard of life. In relation to cultural difficulties, several researches looking into the problems of translation from the English language into the Arabic language has been conducted to date, but only a few attempts have been made looking into doing it from the Arabic language into the English language. To the knowledge of the researcher, this paper is one of the few studies that have highlighted the importance of culture in translating culture-specific concepts from the Arabic language into the English language.

\section{Literature Review}

This section comprehensively reviews the relationship between cultures and languages and the effects of cultures on translation as reported in related studies in the literature.

\subsection{The relationship between culture and language}

The unique connection identified between languages and cultures has encouraged people from various backgrounds to explore it in great detail. It is universally acknowledged that languages are integral parts of cultures, and cultures represent essential functions within languages.(Wardhaugh (2002) in relation to such an argument has rightly highlighted that "culture is socially acquired." Therefore, culture and society supposedly have close links while societies and languages have a close association. In other words, there must be a relationship between cultures and languages. Also, (Davis (1999) claimed that the relationship between cultures and languages was continuously repositioned by both linguists and philosophers in the past. Moreover, (Bloch and Trager (1942) stated that a language is acknowledged as a system in which, arbitrary vocal symbols are used for individual contact with others while a culture is a collection of traditions, principles, behaviours, institutions, and communication patterns that are common, learned and transferred through individuals belonging to communities. The various definitions of language and culture indicate that both are linked closely to each other while culture uniquely appears so inclusive, involving almost every aspect of human lives, even words uttered by individuals in their daily lives. Interestingly, individuals who share similar cultures may have to use their respective languages in exchanging views on such cultures. Therefore, the definitions reported in the literature alone may not be able to offer significant insights in relation to the relationship between cultures and languages. Furthermore, (Newmark (1988) pointed out that translation theorists have identified an intermixed relationship between languages and cultures, maintaining that translation is considered a procedure which involves intercultural interchange. Also, (Tylor (1975) posited that a new description associated with the cultures which 
has widely been cited i.e., "Culture is complicated entirely which usually consists of beliefs, customs, morals, arts, laws, knowledge, and any other attitudes and traditions acquired by, in many cases, the male members of societies. A variety of definitions in relation to culture has been reported by researchers from different approaches (Demo, 1987); (Hantrais, 1989). Some described culture as a set of special crafts; human created the environments, arrangements of social groups, and declared formulas of manners. Other scholars identified culture in more subjective ways, as the universal awareness of individuals belonging to different communities such as world outlooks, traditions, and standard patterns of behaviour and favoured. It can therefore clearly be seen that each one has a different perspective and interestingly, the definition which they stick to may depend on the way cultures influenced him or her. The perceptions which individuals may have on a culture and its individuals can be improved by means of a comprehensive understanding of their language. (Emmitt (1997) disagreed that people grow up under the same behavioural or cultural circumstances, as they may speak different languages and their attitudes may equally be very different. Notably, disparate languages may produce different restrictions; consequently, individuals who belong to similar cultures, but due to geographical factors for instance, speak different languages, usually possess different attitudes toward the world. Furthermore, (Kottak (2007) made a distinction between various levels of culture (e.g., national, international and sub-cultural) and these differences are considered by many as more important in today's world. National culture represents values, mastered behaviour patterns, principles and organizations that are shared by the people belonging to the same population. International culture on the other hand goes outside and across national borders. Due to the fact that culture is disseminated by means of understanding rather than genes, cultural characteristics therefore can neither be disseminated by means of diffusion nor through borrowing from one class to another. As a result of migration, diffusion, globalization and colonialism, the scope of several cultural traits as well as patterns have been widened to global level. Subcultures are different symbol-based habits and customs which are linked along with distinct communities within the same complex community. Attempts of looking for such characteristics can be made in nations around the world like Canada or the United States in which, some subcultures appear to develop from regions, ethnicities, languages, classes and religions. As has been reported in the literature, numerous anthropologists today are reluctant to use the phrase subculture. One of the arguments raised for doing so is that they claim the prefix sub- being inappropriate as the implication is something lower. Thus, subcultures might be construed as more inferior cultures. The effects of language are entirely entwined in cultures i.e., individuals in the course of acquiring a new language may also learn much about a new cultures. In this regard, (Shohamy (2007) pointed out that the understanding of language as open, active, vigorous, continually developing and personal. She also argued that it consists of the rich complexities of communication. It is noteworthy that language is not something to be learned, but a way of seeing, perceiving, and communicating with the world and each culture uses its language differently. In relation to the use of languages, individuals use them to communicate with others and therefore, learning a new language requires knowledge about how to use expressions, grammar, and knowledge of a language and its use for communication purposes with individuals of the culture. The comprehension of language not only takes language as a body of abstract knowledge to be studied but also it takes into account social occasions in which such knowledge can be presented and shared. Also, (Kramsch (1994) reported language as something that individuals utilize in their daily activities and something they use to express, construct and understand meanings and create and maintain social and interpersonal relationships. Many linguists have attempted to associate cultures and languages. Moreover, (Nida (1998) stated that cultures and languages are usually considered as a pair of representational methods. Language forms which are used hold senses that are not similar in meaning owing to the reason that it is connected with language which is narrow than culture. Certain words in certain languages may have connotations which are not similar to that of others. For instance, 'halal', a word which is associated with the Arabic speakers' way of life involves everything to Muslims but to the English language speakers may most probably be confined only to food. Another instance is the word dog. For the Arabic Muslim speakers, it is not a good friend as it is prohibited to rear. Nevertheless, nearly all English speakers associate dog with men's loyal friend an excellent companion. Finally, languages and cultures have complicated links, one over another, and cannot be separated. Each culture can be entirely defined directly by using its language. In the event of involving religions, marriages, and food which are not easy to translate, it is therefore a difficult task for the translators because these terms have concepts in the source text that must be transferred explicitly and with the exact meaning without any alteration being made to the target language. Translation of cultures is one of the most challenging aspects of translation because translators' different cultures may result in different explanations. This research proposes an idea of how culture affects translation.

\subsection{The effects of culture on translation}

The diversity in relation to methods has inspected the cultural implications on translational works. It is important to study these approaches keeping in mind the unavoidability of translational loss which has to be incurred when the text is bound by a particular culture. Considering the variations in relation to the character the text and the similarities concerning the ideal target language text and source language text reader, a critical perspective is therefore to discover how much of missing background information should be presented by the translator who apply these methods. To mitigate such possible problems associated with these methods, it is recommended that to maintain accurate cultural references, certain additions must be made to the target language text. In relation to the close connection identified between cultures and translations, (Snell-Hornby (2006) argued that the translatability of any textual content lies in the degree to which the word is rooted in a particular culture as well as how precisely the distant is separated, on occasions along with the locations. Moreover, (Leppihalme (1997) said how significantly the work is currently carried out in translation research may foreground social and cultural issues of translation. In the event of more emphasis being made on texts in their macro-context instead of only contemplating the translatability of the original textual content, there can 
be room for concerns in relation to the interpretations of the target text in the target language and the cultural context. Furthermore, he said that culturally oriented translation studies do not consider that the source language text and the target language text merely as samples of linguistic materials. The documents of the language of origin deal with a given environment in a given culture in the world, and each may carry a particular meaning and an audience of its own. The link observed between translation and cultures can be considered as almost a trope that has been recognized by researchers of translation since the recognition of the cultural and the orderly development of culture-oriented translational studies which was highlighted by (Lefevere and Bassnett (1990). Translation is indeed a performance in which, it necessarily requires at least two languages and two cultures, and this means translators always face the problems of how to manage the cultural aspects in a source language and the most suitable methods to convey these elements in the target language. Culture in this case may have to be considered in a broad sense, as in anthropological studies. (Hornby (1988) stated that a culture is not only to be regarded as the higher intellectual improvement of individuals, as reproduced in the arts, but it refers to all socially conditioned aspects of human lives. (Katan, 2009) claimed that while time passes and new areas of studies begin to emerge, the concept of culture may also evolve in the minds of individuals. The process of transferring cultural aspects by means of literary translation is considered a difficult task. Culture is a compound gathering of experiences which may condition daily lives as it consists of history, religions, norms, customs and daily usage. It is noteworthy that scholars have claimed that it can be challenging to understand completely. Each one who has made an effort to translate a text may have known that acquaintance with the language alone does not ensure success. Moreover, (Newmark, 1989) stated that "any old fool can learn a language, but it takes an intelligent person to become a translator". Furthermore, (Paluszkiewicz-Misiaczek (2005) said that besides an impeccable level of understanding in relation to both the source and the target language, which includes words and expressions, sentence structures, spellings, and utterances, the translators also have to acquire the knowledge of sociolinguistics, which may assist them with comprehending the text within its context, to decide its functions and guess who is going to be the readers. Moreover, (House (1997) noted that translation is not only a linguistic activity as it is also about communication activities involving various cultures. Translation always contains both languages and cultures since languages and cultures are in many cases intertwined. In the course of translational process, not only can the two languages be used but also the two cultures may notably come into close contact. Translating is a form of intercultural communication. In this regard, (Hongwei (1999) asserted that language contains pictures of a culture and may also reflect other components of a culture to support them, spread them, and contribute to developing other cultures at the same time. The special characteristics of language appear to separate it from all other aspects of the associated culture and make it remarkably significant for the transfer of culture. The formation and development of all aspects of a culture are inextricably linked to one another. In relation to this, (Newmark (1988) stated that food terms are notably subject to the broadest range of translation. The terms under this category are further complicated because of the unfamiliar elements present within it. Concerning food habits, they may not be translatable to target language readers as they may not have heard of the food. For example, certain foods are prepared only during certain festivals. In Sudan for instance, in the month of Ramadan, people make special kinds of food, which are local food items. Dress and ornaments used, and the symbols behind each of them may show differences in cultures, and this may be considered as a problem for a translator. For example, in the world of the Arabs, the concept of women wearing ornaments is meant to be part of their beauty, but for western women, it may sound quite strange. Dressing in the Arab world can be considered quite different to some quarters as it represents national dignity. For example, a widow in the context of Arabic countries has to abide by the norms in Saudi, for instance, she must wear white clothes upon the demise of her spouse, but for English speakers, it may sound strange. Rituals and customs are components of cultures, but the importance and hidden symbolism behind it may turn out to be obstacles to translators. For example, in a marriage ceremony of Christians, couples exchange kisses in the church. On the contrary, Saudi Arabia, being an Islamic country may consider it as something completely unacceptable. Lastly, geographical and environmental components are also part of the cultures. For example, snow is a part of the Inuit life in Alaska. In Saudi, people may not be aware of the concepts of cold and snow, and there is no similar idea to express different kinds of snow. In relation to this, (Aziz and Lataiwish (2000) said that cross-cultural translations might have to face many difficulties in translation involving different languages. In this regard, it is worth highlighting that the translational works involving the English language, which represents the western cultures, and the Arabic language, which belongs to the oriental Islamic culture may always have to deal with the cultural gap in translation. Following are the types of cultural problems which may have to be dealt with:

1. A geographical culture which means two cultures involved in translational works may have different backgrounds related to topics such as animals, plants, and climate issues. For example, in the context of the Arabic world, Saudi is commonly described by a hot and dry weather like most of the North African countries, while, the culture of Western Europe is rather cold and snowy. Within these two cultural frameworks, the various geographic terms may need a different shade of meaning for the translators to use them in their works

2. Religious culture may have deep roots in several various cultures and may reveal how individuals of societies speak and perform their norms and behave. However, some societies are more religion conscious than others. In general, the influence of religion on individuals is useful and more apparent in the East than in the Western context.

3. Social culture beliefs may cause some difficulties. The challenges may include the approaches of various societies toward love, marriage and the concept of moral standards.

4. The material has a wider sense and may range from things such as means of transport, food and other objects that individuals use in their daily lives. This material may be unique and different from one society to another. Developed 
countries may have to deal with various things belonging to this category like, E-mail history, which may not be found in some countries.

5. Linguistic culture means how people see the external world and what differences they draw from different parts are likely to be reflected in their language use. Some linguists made the distinction among three basic language functions which are textual, interpersonal and ideational. In the ideational function, for example, the English language appear to have two terms as far as the number order is concerned, the singular and plural, whereas Arabic defines it by three terms namely, singular, dual and plural. In conclusion, cultural translation may need a multi-pronged approach to handle the problems associated with translational works. It is concerned with the writer's relationship to these issues and with the reader's relationship to the person who reads it. Such an approach has to be expressed in possibly a high-quality translation work. The translator must transmit this particular cultural quality from the source language into the target language. Most translations intend to provide, though imperfectly, a replacement for the language of origin, making it accessible to people who can comprehend the language in which it is produced. This can be considered as a substantial burden on the translator.

\section{Objectives of the Study}

1. To assess the effects that cultural knowledge may have on students translating culture-specific concepts.

2. To identify the circumstances which may cause problems to students in translating culture-specific concepts?

\section{Research Questions}

1. What are the effects of cultural knowledge on translating specific cultural concepts?

2. What are the difficulties that the students may have to encounter in translating culture-specific concepts?

\section{Significance of the Study}

A considerable amount of studies has to date been carried out to explore the problems that translators encountered in the course of translating, in general, but such studies practically dealing with specific cultural concepts in relation to the Arab world are comparatively smaller and in such studies, the focus was on one particular category such as collocations, proverbs and idioms. On these grounds, the present study was set out to bridge this gap identified in the literature since its purpose is examine the problems taking into the consideration all kinds of specific cultural concepts. It is hoped that the findings of this paper and recommendations made for future research may help other researchers.

\section{Sample of the study}

The sample of the study was drawn from the final year Al Aradh college- at the University of Jazan. There were various reasons for recruiting this group of as the respondents for this study. First, the criteria for selecting the students were based on their relatively higher performance in their last exams for which, they obtained above $70 \%$. Second, they were at the end of their undergraduate program and would soon be posted to different schools all over Saudi Arabia to begin their career. Third, they were native speakers of the Arabic language. Altogether, there were 35 students, and their ages ranged between 20 and 22 years old.

\section{Instrument of the study}

In this study, the researcher employed one instrument to collect the data. A special translation test was carried out to fulfil the requirements of the present paper. The test contained 18 specific cultural concepts extracted from the Arabic language.

\section{Results}

Following the data collection, the data were then analyzed in accordance with the criteria namely, the wrong word, the right word, transliteration, incomplete meaning and no answer.

Table 1 shows the results of the specific religion concepts and it should be highlighted that $71 \%$ of the responses were wrong. It can be concluded that the students had minimal information about the cultural concepts of English throughout their studies as the overall percentage of the correct responses was only 16\%. Moreover, the various cultural products

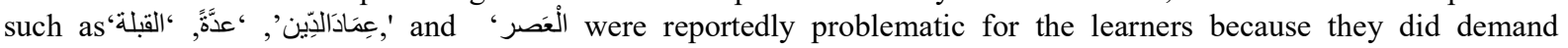
particular information in relation to the English culture. The percentage for these types of words was at $71 \%$, and thus, it can be concluded that these words were not simple to translate.

Table 1. Religion

\begin{tabular}{lll}
\hline Measuring unit & Frequency & Percent \\
\hline Right word & 16 & 16.0 \\
Wrong word & 71 & 71.0 \\
Transliteration & 12 & 12.0 \\
Incomplete meaning & 1 & 1.0 \\
Total & 100 & 100.0 \\
\hline
\end{tabular}


Table 2 demonstrates the results of the test with regards to the specific cultural food concepts and $64 \%$ of the responses were wrong. The total percentage of correct responses was at $7 \%$, which indicates that the learner has very limited information or knowledge about the cultural concepts of English throughout their studies. Apart from that, it was also discovered that words embedded with the cultural objects like 'لفلافلَ' were problematic for the learners because they did demand for some information about the English culture. The entire percentage for these types of words was $64 \%$, which further confirmed that these words were not simple to translate.

Table 2. Food

\begin{tabular}{lll}
\hline Measuring unit & Frequency & Percent \\
\hline Right word & 7 & 7.0 \\
Wrong word & 64 & 64.0 \\
Transliteration & 3 & 25.0 \\
Incomplete meaning & 1 & 3.0 \\
Total & & 1.0 \\
\hline
\end{tabular}

Table 3, which indicate the results of the test with regards to the specific cultural food concepts, $60 \%$ of the answers were wrong. However, the results suggested that the students had insufficient knowledge about the English cultural concepts during their studies since the total percentage of correct answers was at $32 \%$. The results also revealed that

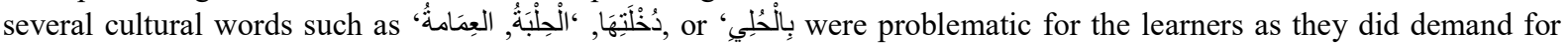
particular information in the English culture. The entire percentage for these types of words was at $60 \%$, and this has confirmed that these words were not simple to translate.

Table 3. Marriage

\begin{tabular}{cll}
\hline Measuring unit & Frequency & Percent \\
\hline right word & 32 & 32.0 \\
wrong word & 60 & 60.0 \\
Transliteration & 8 & 8.0 \\
Total & 100 & 100.0 \\
\hline
\end{tabular}

\section{Discussion}

The findings of the present study suggest that there are hindrances and difficulties faced by the students of AL Aradh College in translating particular food, religious, and marriage cultural concepts from Arabic to English. The analyses helped in classifying those translation issues into noticeable domains, in which several translations issues existed. Moreover, the analysis has also identified which concepts were the most problematic in the translation process. The results of the present study suggest that the interpretation of particular food, religious and marriage cultural concepts among these students was insufficient and thus, they appear to have inadequate knowledge of the target language culture.

\subsection{Specific religious cultural concepts}

The findings of the present study showed that non-equivalent specific religious cultural concepts are the actual barriers for students in translating Arabic language words into English language words. Translators of non-equivalent specific religious cultural concepts may have to be extremely conscious of the differences between Arabic language concepts and beliefs and English language concepts and beliefs. This is echoed in ((Dweik and Suleiman, 2013) study in which they reported that context has to be taken into consideration. For instance, the term waَدادالَدِّن, which means prayers or the regular ritual prayer imposed upon each Muslims as one of the five pillars of Islam, belongs to the non-equivalent specific religious cultural concept. Hence, the English translation of this word varies among the sampled participants which concurred with the recent findings of a study by (Mahmoud 2013). It should be noted that the challenge in translating such words is due to the concept embedded with the cultural variations between the source language and the target language. Apart from that, words that show non-equivalent specific religious cultural concepts may be problematic because the translator may have difficulties in finding the equivalent words in both languages. For instance, one of the participants translated the concepts of عَمَادَالدِّين as prayers, which have connection with religious actions. It is noteworthy that the findings of the present study revealed that the religious cultural concepts in languages are challenging in the translation procedure (Maasoum and Davtalab, 2011). (Ghazala,2002) claimed that all Islamic terms 
and concepts can be translated into the target language, i.e., not by offering their full English equivalents but by setting a method for handling the non-equivalence. In this situation, the application of loan words with a brief description is considered more accurate and more precise in representing the full meaning of these terms. Furthermore, translators have to consider the specific cultural conditions because in this context, the Saudi belongs to an Islamic society whereas the English speakers are more or less from the Christian society. Translating specific religious or cultural concepts is, therefore, difficult. The level of difficulties, complexities and probability of translating non-equivalent specific religious cultural concepts to languages of different cultures maybe influenced by the translators' backgrounds. The translator's experience and mental disposition at the time of translating such terms, i.e., non-equivalent specific religious and cultural concepts, play important role because sometimes, it may affect the quality of the translation. (Wilss, 1982) claimed that the achievement of translators in lies on several aspects namely, their mental personality, knowledge of the text, the degree of difficulty of the relevant terms and the translator's capability level.

\subsection{Specific food culture terms}

The finding of the present study indicates that students find it difficult to translate the specific food cultural concepts from Arabic to English. This is due to the fact that food can be culturally complex. However, translators should take into account all the extra- linguistic factors which are similar to the finding reported in (Saleh et al., 2011). In translating term like الملوخية mloukhiya which means the leaves of corchorus (a kind of vegetable in Sudan), 59\% of the participants gave the wrong word, which was considered as a problem faced by the participants. It should be noted that, the process of translating non-equivalent specific food cultural concepts appears to be more challenging due to the differences between the culture of both languages and the meals that are usually new and unknown in the target culture. For instance, some sampled participants translated the word الملوخيه as green leaves which is considered wrong. Translators are required to think about various cultural factors that may affect the process of translating food terms in order to create a suitable and acceptable translation (Saleh et al., 2011) posited that the use of transliteration in translating nonequivalent specific food cultural concepts maybe helpful in narrowing the gap between the target language readers and the source language readers, which in turn may avoid distortion translations. For example, one of the participants translates the same word الملوخية as mloukhiya. Non-equivalence specific food cultural concepts are perceived as difficult in the process of translation not only because of the associations with the target language culture, but also due to the narrow choices of suitable methods in dealing with these words. The same findings are echoed by (Saleh et al., 2011)According to (Newmark, 1988), the cultural aspect is the most significant aspect in translation as cultural dimension has reportedly create problems in translation for which translators should be careful and sensitive in order to decrease the cultural gap between the languages. In translating the term الْفَلَفِل falafel (a popular to Middle Eastern meal, which commonly stuffed in a pita), $62 \%$ of the participants gave wrong answer and this is considered a problem faced by the participants. Another example is the word (dough) were translated wrongly by most of the participants. Moreover, the participants used transliteration which causes the target term to be associated with the source language term and without any explanation. The same findings were reported by (Saleh et al., 2011)Also, one of the participants translated the same word الْفَلَفِ as falafel without any brief explanation. It is deemed significant to have a strong knowledge of what the background and purpose of the term is in order to select suitable strategies throughout the translation process. It is noteworthy that the aim of doing translation is to clarify the concepts of food culture to the target language reader and similar findings were reported recently by (Nyrén 2013).

\subsection{Specific marriage cultural terms}

Findings from the data analysis revealed that cultural concepts in relation to specific marriages may pose real problems for students in translating from the Arabic language into the English language. In translating the term, ليلة دخلتها which means the fulfilment of the wedding ceremony among the sampled in this study, $82 \%$ of them provided the wrong answer, which indicate that this can be a problem faced by the participants. For example, one of the participants

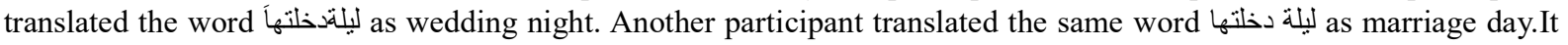
was found that the majority of the participants were unable to translate terms like ليلة دخلتها which means wedding's fulfilment because the term reportedly has no equivalent in the English language. The outcome of the test also revealed that selecting and determining the suitable translation method was an additional difficulty that students had to face. Several learners adopted either the literal translation or transliteration strategy in translating the term بِ بالْخِلِ which means 'glories' without providing any description for the target language receptor as reported recently by (Dweik and Suleiman, 2013). The outcomes of the test showed that the majority of the participants faced difficulties when they had to deal with words which are rooted in culture. These obstacles were primarily about getting the suitable corresponding terms and adopting the appropriate methods of translation to transfer the sense of the words into the target language. Cultural concepts in relation to specific marriage are more challenging than normal plain language words because they are extremely rooted in culture and usually do not have any equivalent and literal meaning because of cultural differences observed between both languages. Such a finding was similarly reported by(Dweik and Suleiman, 2013). Most participants who studied the English language find that the translation from Arabic language into the English language as much more problematic than translation from the English language into Arabic due to the fact that they are more acquainted with the various linguistic and cultural aspects of their languages than the English language as has been argued by (Jabak, (2012).

To overcome the cultural knowledge problems in translating specific cultural concepts, the students revealed their inclination of paraphrasing as an alternative to finding the equivalent in the second language. Therefore, inadequate knowledge of cultural may lead to the students to make clear descriptions about the cultural specific cultural concepts. 
Hence, this approach revealed that the learners had no proficiency skill associated with modifying specific cultural concepts from the original language to the second language. It is noteworthy that the learners should be more cautious about the specific cultural concepts. Also, they should make extra attempts to understand and collect information with regards to these sorts of ideas and discover a translation strategy which corresponds with original language rather than to acknowledge these ideas as items that should be transferred in their original form.

\section{Conclusion}

Culture can be considered as a crucial part of language learning. The researcher deems that second language teachers must take the initiative to educate the students about the distinct cultural concepts. Insufficient cultural awareness may create difficulties in understanding the full message of the different cultural concepts, especially when interpreting them into the target language. It is noteworthy that the study of culture may not be seen as an essential issue in language learning. However, culture and language are intertwined, in which learners should be able to understand the cultural meaning as well as to produce them accurately in the target language. Students of the second language can attain an adequate mastery of the target language if they have enough cultural knowledge. The results of this study have answered the first research question, i.e., what are the effects of culture when translating cultural-specific concepts from Arabic to English. The effects of culture when translating non-equivalence cultural specific concepts from the Arabic language to the English language was examined and identified and It is found that, due to the absence of cultural knowledge among the students, translating the cultural specific concepts is problematic. The same findings are reported by (Olk, 2003), who reported that the learners' insufficient awareness about the English culture can contribute to the adoption of improper translation strategies. Moreover, the findings of the present study have also answered the second research question, i.e., what are the difficulties faced by the students in translating cultural specific concepts. It is worth highlighting that most cultural specific concepts represent implicit meanings, which are hidden by the students' linguistic structures. These words are conventionally, culturally and pragmatically associated with the Arabic language. The difficulty of the translation process of the cultural specific concepts often becomes unavoidable due to the fact that cultural concepts of the source language are embedded with connotative meaning. Thus, the readers of the target language may not be able to grasp the real meaning of the words, in which they may only understand some linguistic elements of those particular words. In this regard, the translator should use the compensation strategy in order to make the representation look clearer as reported by (Garcia, 1996) In order to meet the objectives of the present study, the researcher has highlighted the challenges and hindrances that were encountered by the students when translating particular food, religious and marriage cultural concepts from the Arabic language to the English language. Cultural differences amongst languages are reportedly to be the primary reason for the difficulty of translating among students due to the fact that food, religious, and marriage are embedded with cultural concepts which have long cultural inheritance behind them (Wilss, 1982).

\section{References}

Al Agha, B. A. (2009). The translation of fast-food advertising texts from English to Arabic (Master's dissertation, University of South Africa).

Alousque, I. N. (2010). Cultural domains: Translation problems. Revista de Lingüística y Lenguas Aplicadas, 4(1), 137145.

Aziz, Y. Y., \& Lataiwish, M. S. (2000). Principles of translation. Department of English. University of Garyounis.

Bloch, B., \& Trager, G. L. (1942). Outline of linguistic analysis. Baltimore: Linguistic Society of America.

Davis, L. (1999). Doing culture: Cross-cultural communication in action. Beijing: Foreign Language Teaching and Research Press.

Demo, P. (1987). Sociologia: uma introdução crítica. São Paulo: Atlas.

Deretti, T. (1980). Introdução à Sociologia. Porto Alegre: FEPLAM.

Duranti, A., \& Goodwin, C. (1992). Rethinking context: Language as an interactive phenomenon. Cambridge: Cambridge University Press.

Dweik, B. S., \& Suleiman, M. (2013). Problems encountered in translating cultural expressions from Arabic into English. International Journal of English Linguistics, 3(5), 47.

Emmitt, M., \& Pollock, J. (1997). Language and learning: An introduction for teaching (2nd ed.). Melbourne: Oxford University Press.

Garcia, A., Francisco (1996). On translating figurative language from English into Spanish: A perceptual problem. Babel, 42(3), 158-165.

Ghazala, H. (2002). Tarjamatul mustalahatil islamiati. Symposium on the Translation of the Holy Quran. Al-Madinatul Munawwaratu: Kingdom of Saudi Arabia.

Hantrais, L. (1989). The undergraduate's guide to studying languages. London: CILT.

Hongwei, C. (1999). Cultural differences and translation. Meta: Journal des traducteurs / Meta: Translators' Journal, 44(1), 121-132. 
Hornby, S. (1988). Translation studies: An integrated approach. Amsterdam and Philadelphia: Benjamins Publishing House.

House, J. (1997). Translation quality assessment: A model revisited. Turbringen: Narr.

Jabak, O. (2012). Translation difficulties: Analysis of the most commonly recurring difficulties facing Arab students when translating into English. London: LAP LAMBERT Academic Publishing.

Kashgary, A. D. (2011). The paradox of translating the untranslatable: Equivalence vs. non-equivalence in translating from Arabic into English. Journal of King Saud University-Languages and Translation, 23(1), 47-57.

Katan, D. (2009). Translation as intercultural communication. The Routledge Companion to Translation Studies, 74-92.

Kottak, C. (2007). Mirror for humanity: A concise introduction to cultural anthropology (5th ed.). New York: McGrawHill.

Kramsch, C. (1994). Context and culture in language teaching. Oxford: Oxford University Press.

Lefevere, A., \& Bassnett, S. (1990). Introduction: Proust's grandmother and the thousand and one nights: The 'cultural turn'in translation studies. Translation, History and Culture, 1-13.

Leppihalme, R. (1997). Culture bumps: An empirical approach to the translation of allusions (Vol. 10). Clevedon, UK: Multilingual Matters Limited.

Maasoum, S. M. H., \& Davtalab, H. (2011). An analysis of culture-specific items in the Persian translation of “dubliners" based on Newmark's model. Theory and Practice in Language Studies, 1(12), 1767-1779.

Mahmoud, M. M. A. (2013). Investigating some lexical problems in English - Arabic translation. International Journal of Scientific \& Engineering Research, 4(4), 1016-1082.

Newmark, P. (1988). A textbook of translation (Vol. 1). New York, USA: Prentice Hall.

Newmark, P. (1989). Paragraphs on translation (Vol. 1): Bristol, UK: Multilingual Matters Limited.

Newmark, P. (1991). About translation (Vol. 74). Clevedon, UK: Multilingual Matters Limited.

Nida, E. A. (1998). Language, culture, and translation. Foreign Languages Journal, 115(3), 29-33.

Nyrén, J. (2013). Translating American food culture from English to Swedish: A study of cultural references in translation. Linnaeus University, Sweden.

Olk, H. (2003). Cultural knowledge in translation. ELT Journal, 57(2), 167-174.

Paluszkiewicz-Misiaczek, M. (2005). Strategies and methods in dealing with culture specific expressions on the basis of Polish-English translations of certain administrative and institutional terms. In Proceedings from the Eighth Conference of English, American and Canadian Studies:(linguistics, methodology and translation) (Vol. 3, pp. 243). Masaryk University.

Saleh, K., El-Isa, S., Sameer, E. L., An, O., \& Hirzallah, R. (2011). Translating restaurants menus from English into Arabic: Problems and strategies (Unpublished Master's thesis, An-Najah National University).

Shohamy, E. (2007). Language tests as language policy tools. Assessment in Education, 14(1), 117-130.

Snell-Hornby, M. (2006). The turns of translation studies: New paradigms or shifting viewpoints? John Benjamins Publishing Company.

Tylor, E. B. (1975). Sir 1871 primitive culture: Researches into the development of mythology, philosophy, religion. Language, Art and Custom. London: J. Murray.

Venuti, L. (2012). The translation studies reader. London: Routledge.

Wardhaugh, R. (2002). An introduction to sociolinguistics (4th ed). Oxford: Blackwell Publishers Ltd.

Wilss, W. (1982). The science of translation: Problems and methods (Vol. 180). John Benjamins Pub Co. 